\title{
Radiation Resistance of a Structural Material Based on Modified Titanium Hydride
}

\author{
R. N. Yastrebinsky, V. I. Pavlenko, A. A. Karnauhov, N. I. Cherkashina $(\mathbb{D}$, \\ A. V. Yastrebinskaya, and A. I. Gorodov \\ Institute of Chemical Technology, Belgorod State Technological University Named After V. G. Shukhov, Belgorod 308012, Russia \\ Correspondence should be addressed to N. I. Cherkashina; natalipv13@mail.ru
}

Received 27 October 2020; Revised 10 March 2021; Accepted 19 March 2021; Published 30 March 2021

Academic Editor: Carlo Sborchia

Copyright (C) 2021 R. N. Yastrebinsky et al. This is an open access article distributed under the Creative Commons Attribution License, which permits unrestricted use, distribution, and reproduction in any medium, provided the original work is properly cited.

\begin{abstract}
This work investigates the radiation resistance of a structural material based on modified titanium hydride and a Portland cement in a flux of neutron and $\gamma$-radiation. An assessment of the geometric and physicomechanical properties is given, along with the surface structure of irradiated cement composites, and the phase composition of the main hydrosilicates of the hydrated cement matrix during its $\gamma$-irradiation. It is shown that the use of a shot of titanium hydride increases the radiation resistance of radiation shielding based on a cement matrix, in comparison with the unmodified shot. A composite based on a modified shot of titanium hydride retains its basic properties after $\gamma$-irradiation, at an absorbed dose of up to $10 \mathrm{MGy}$. At an absorbed dose of $2 \mathrm{MGy}$ in the Portland cement matrix of a composite based on a modified shot of titanium hydride, the formation of suolunite hydrosilicates occurs. It was established using X-ray fluorescence that, in the titanium hydride, a redistribution of the electron density occurs at an absorbed dose of $\gamma$ radiation of $5 \mathrm{MGy}$, caused by structural phase changes due to the ongoing dehydrogenation processes.
\end{abstract}

\section{Introduction}

When designing a radiation protection structure, it is necessary to use materials that retain their operational properties under the influence of reactor irradiation (physicomechanical, physicochemical, structural, thermophysical, etc.). Radiation exposure, to a large extent, affects the mechanical properties of materials, their strength, and ductility. This influence must be taken into account when building critical structures for radiation protection (nuclear and thermonuclear reactors, spacecraft, etc.) from ionizing radiation. Radiation-induced changes in mechanical properties is the result of a complex of various processes occurring in the structure of the material, including the formation of point defects and their accumulations (dislocation loops and pores); the formation of gaseous impurities (helium, hydrogen), stimulating gas swelling and embrittlement; decomposition of solid solutions; formation and dissolution of second phases; formation of radiation- stimulated diffusion and segregation of components; and radiation creep [1-4].

The ability of materials to retain their basic properties after irradiation (within the specified range) is determined by the concept of radiation resistance. These properties, first of all, include the strength characteristics of the material, changes in its geometric parameters, as well as radiationprotective properties. The quantitative characteristic is the maximum value of the absorbed radiation dose at which the material changes its properties to a subcritical level. The concept of the subcritical level depends on the specific operating conditions of the radiation-protective material. For example, for materials inside the elements of metal structures, radiation resistance is understood as the absorbed dose of gamma radiation causing the formation of macrocracks in the material. For materials operating in a stressed state, radiation resistance is determined by a decrease in strength characteristics, the specific value of which depends on the function performed by the material. 
Many well-known studies have been devoted to the subject of radiation resistance of materials, in particular, structural steels, various metals, and their alloys, as well as the mechanisms of radiation defect formation occurring during irradiation. The problem of radiation-induced degradation of the mechanical properties of materials is of particular importance when considering the almost twofold extension of the service life of nuclear reactors. For this reason, increasing the radiation resistance of structural and functional materials is one of the most important in modern radiation materials science [5-11].

Composite materials based on cement binders (concretes) containing various functional fillers have found the most use as radiation protection materials. This is due to the possibility of obtaining materials of various geometries and filling hollow radiation-shielding metal structures with mobile cement mortar. At the same time, the concrete has high radiation resistance (it does not change the geometric dimensions in the integral neutron fluxes up to $10^{21}$ neutrons $/ \mathrm{cm}^{2}$ ) and has only negative radiation deformations (reduces the volume) [12-15].

When exposed to gamma radiation, the mechanism of cracking in Portland cement concrete is determined by the dislocation of atoms in the cementing phases [16], radiolysis of water [16-21], dehydration of cement hydrates $[17,18,21]$, and amorphization of aggregates [22-24]. Hydrogen ions formed as a result of water radiolysis are capable of being attracted by hydrated ions of clinker minerals, forming new phases, solid solutions, and intrusions in the structure of cement paste [25]. The impact of gamma rays on chemically bound water may directly impart sufficient energy in order to dehydrate phases such as $\mathrm{C}-\mathrm{S}-\mathrm{H}$ or $\mathrm{Ca}(\mathrm{OH})_{2}$ [26]. Neutron radiation can lead to an increase in the volume of the filler. The change in the properties of concrete shielding during irradiation mainly depends on changes in the properties of aggregates and on the interphase interaction between the aggregate and the cement matrix. Concrete is least susceptible to cracking processes, in which the radiation deformations of the aggregate are close to or less than the radiation deformations of the concrete itself [27].

One of the most effective fillers used for reactor protection is titanium hydride, in the form of spherical granules (shot). Its high hydrogen content (up to 3.6 wt. \%) and density (up to $3.8 \mathrm{~g} / \mathrm{cm}^{3}$ ) make it possible to effectively use titanium hydride to simultaneously attenuate both neutron and $\gamma$ radiation [28-32]. Previous reports [33-38] have shown that modification of the surface of titanium hydride shot with borosilicate coatings or ion-plasma spraying of titanium metal significantly increases its thermal stability. The creation of a modifier shell on the surface of a shot of titanium hydride prevents thermal diffusion of hydrogen into the environment and increases the initial temperature of dehydrogenation to $500^{\circ} \mathrm{C}$. This expands the possibility of using titanium hydride as a radiation protection material.

However, studies of the radiation resistance of a cement composite based on shot of titanium hydride have not been carried out. To this end, this paper presents the results of studies of the effect of high-energy $\gamma$ and neutron radiation on the structure and properties of a radiation protection material, based on a modified shot of titanium hydride and a Portland cement binder. For comparison, the results of studies for cement stone and a composite based on an unmodified shot of titanium hydride are also presented.

\section{Materials and Methods}

2.1. Materials. The following materials were used as objects of research:

(1) A composite material based on a mixture of a modified shot of titanium hydride, Portland cement, water, and plasticizing additives was examined. The ratio of Portland cement and a shot of titanium hydride in the mixture was $1: 3$; the water-cement ratio was 0.3 . Titanium hydride was modified by depositing a borosilicate shell on its surface [35]. The material was obtained by vibration compaction on the KV-56 stand, with a vibration frequency of 3000 counts/min. After compaction, the material was hardened for $28 \mathrm{~d}$ and then heat-treated at $300^{\circ} \mathrm{C}$ for $500 \mathrm{~h}$.

The chemical composition of the composite material is shown in Table 1.

(2) Composite material based on an unmodified shot of titanium hydride, Portland cement, water, and plasticizing additives. The ratio of Portland cement and a shot of titanium hydride in the mixture was 1 : 3 ; the water-cement ratio was 0.3 .

The material was obtained by vibration compaction on the KV-56 stand, with a vibration frequency of 3000 counts/min. After compaction, the material was hardened for $28 \mathrm{~d}$ and then heat-treated at $300^{\circ} \mathrm{C}$ for $500 \mathrm{~h}$.

(3) Cement paste based on a mixture of Portland cement and water. Water-cement ratio 0.3 .

The material was obtained by vibration compaction on the KV-56 stand, with a vibration frequency of 3000 counts/min. After compaction, the material was hardened for $28 \mathrm{~d}$ and then heat-treated at $300^{\circ} \mathrm{C}$ for $500 \mathrm{~h}$.

2.2. Methods. 1. Irradiation of the composite material in a neutron flux was carried out in the zone of the reflectors of the core of the IVV-2M research nuclear reactor, at a temperature gradient on the composite sample of no more than $1.5^{\circ} \mathrm{C} / \mathrm{mm}$. The temperature gradient on the composite sample was determined on the basis of the thermal calculation of the reactor irradiation device taking into account the required neutron fluence of $2 \times 10^{19}$ neutrons $/ \mathrm{cm}^{2}$. The calculated value of the heat transfer coefficient was taken equal to $8000 \mathrm{~W} / \mathrm{m}^{2} \cdot \mathrm{b} 7 \mathrm{~K}$, the specific energy release of the composite material was $0.0216 \mathrm{~W} /(\mathrm{g} \bullet \mathrm{MW})$.

The irradiation device consisted of an aluminum ampoule with ten composite samples, placed in a vessel sealed from the reactor water, which, in turn, was installed in the "wet" channel of the reactor (Figure 1). The geometry of the material samples was a cylinder $22 \mathrm{~mm}$ in diameter and $45 \mathrm{~mm}$ in height. 
TABLE 1: Chemical composition of a composite material based on a modified shot of titanium hydride and Portland cement after heat treatment at $300^{\circ} \mathrm{C}$ for $500 \mathrm{~h}$.

\begin{tabular}{lccccccccc}
\hline \multicolumn{1}{l}{ Content [wt. \%] } \\
\hline $\mathrm{TiH}_{1.8}$ & $\mathrm{SiO}_{2}$ & $\mathrm{Al}_{2} \mathrm{O}_{3}$ & $\mathrm{Fe}_{2} \mathrm{O}_{3}$ & $\mathrm{CaO}$ & $\mathrm{MgO}$ & $\mathrm{SO}_{3}$ & $\mathrm{Na}_{2} \mathrm{O}$ & $\mathrm{K}_{2} \mathrm{O}$ & $\mathrm{H}_{2} \mathrm{O}$ \\
77.71 & 4.70 & 1.21 & 0.99 & 14.03 & 0.33 & 0.51 & 0.12 & 0.07 & 0.33 \\
\hline
\end{tabular}

The samples were located symmetrically relative to the central plane of the reactor core. Inserts between the samples in the form of steel washers served to equalize the temperature of the samples located below and above the central plane of the core, where the gamma field is weaker. The body of the irradiation device was sealed from water circulating in the gap between the walls of the body and the "wet" channel.

The samples were located symmetrically, relative to the central plane of the reactor core. The arrangement of the samples ensured their irradiation in the temperature range $245-255^{\circ} \mathrm{C}$, with an average flux density of fast neutrons ( $E$ $>0.5 \mathrm{MeV}$ ) for $15 \mathrm{MW}$ power, the reactor power $5.55 \bullet 10^{12}$ neutrons $/\left(\mathrm{cm}^{2} \bullet \mathrm{s}\right)$, and a fluence of $2 \times 10^{19}$ neutrons $/ \mathrm{cm}^{2}$. The temperature in the material sample was determined by the calculation method based on the temperature of the coolant in the cooling zone of the body of the irradiation device and the heat transfer coefficient. The calculation of the temperature fields in the samples of the material of the assembly of the irradiation device was carried out using the calculation program "ANSYS" [39]. The calculation results are presented in Figures 2 and 3.

For research, 20 samples of composites were used, obtained under the same conditions from one batch of a composite mixture. The conditions of the reactor tests made it possible to irradiate one batch of samples (10 samples) simultaneously loaded into the irradiation device. Investigations of changes in the properties of the composite samples were carried out after the collection of the average fast neutron fluence $(E>0.5 \mathrm{MeV})$ over the samples, equal to $1.9 \times 10^{19}$ neutrons $/ \mathrm{cm}^{2}$. All work with irradiated samples was carried out remotely in hot chambers. The accuracy of determining the geometric dimensions and mass was the same as for nonirradiated samples.

2. Irradiation of the composite material in a flow of highenergy $\gamma$ radiation was carried out at various dose loads in the barrier geometry of the shield, on a ${ }^{60} \mathrm{Co}(E=1.3 \mathrm{MeV})$ research $\gamma$ installation with a dose rate of $21 \mathrm{kGy} / \mathrm{h}$. For the experiment, we used 25 samples based on an unmodified fraction of titanium hydride (does not contain a borosilicate shell) and 25 samples based on a modified fraction of titanium hydride (contains a borosilicate shell). In each experiment, 5 samples of composite material $3 \times 3 \times 3 \mathrm{~cm}$ in size, mounted parallel to the plane of a wide beam of gamma radiation, were simultaneously exposed to irradiation until they reached the appropriate dose of radiation. In each experiment, all five samples received the same radiation dose. Five samples from each batch were evaluated as controls. The geometry of the experiment is shown in Figure 4. The control of integral doses of irradiation of the samples was performed using cellulose triacetate dosimetric films. The temperature of the samples was measured using a thermocouple.

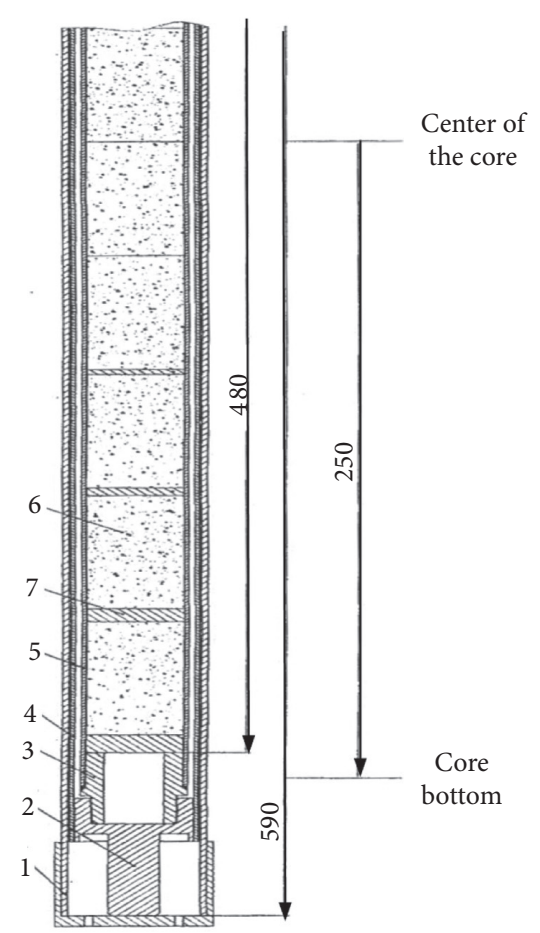

FIgURE 1: Irradiation device (dimensions are in $\mathrm{mm}$ ): 1: «wet» channel body, 2: irradiation device shank, 3: ampoule shank, 4: irradiation device body (diameter $28 \mathrm{~mm}$, wall thickness $1 \mathrm{~mm}$ ), 5: ampoule body (diameter $25 \mathrm{~mm}$, wall thickness $1 \mathrm{~mm}$ ), 6: material sample, and 7: washer.

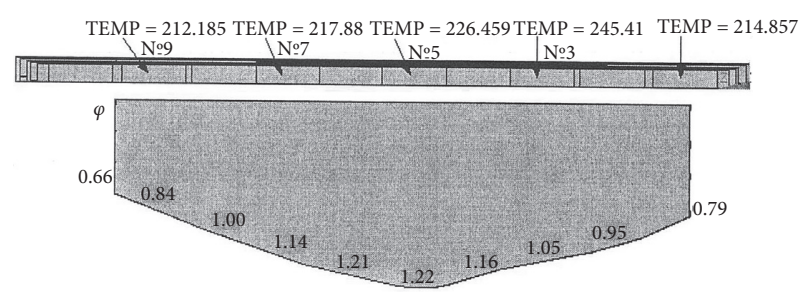

FIgURE 2: Temperature in material samples and a graph of the relative distribution of the neutron flux density ( $\varphi$, relative units) along the height of the irradiation device assembly.

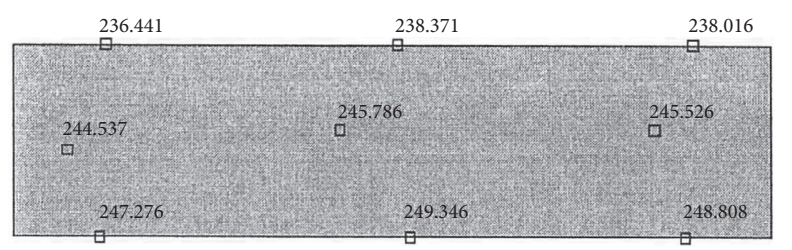

Figure 3: Calculated values of temperature $\left({ }^{\circ} \mathrm{C}\right)$ in sample No. 3 from the axis to the outer heat-removing surface. 


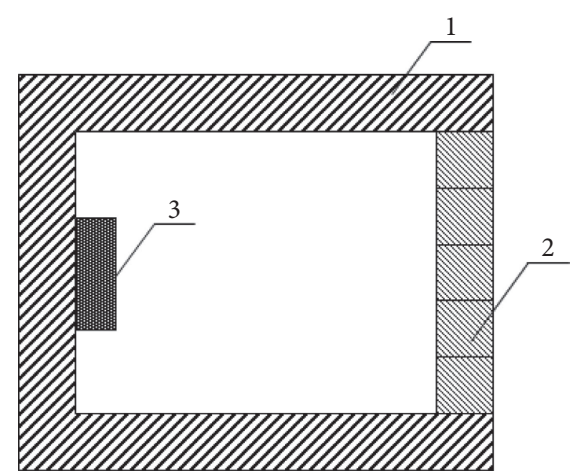

Figure 4: Geometry of the composite material irradiation in the high-energy gamma-radiation flow: 1: protective shield; 2 : material samples; and 3: a source of gamma radiation ${ }^{60} \mathrm{Co}$.

3. The microstructure of the surface of the composite material was studied by scanning electron microscopy (SEM) in the diffraction mode of reflected (backscattered) electrons. In this mode, the contrast largely depends on the crystallographic orientation of the grains relative to the sample surface and on the chemical composition of the phases. In this case, the microstructure of the material surface can be studied without preliminary etching of the section. The studies were carried out on a Quanta 600 FEG SEM (FEI Company, USA), at an accelerating voltage of $20 \mathrm{kV}$ and an electron beam current of $36 \mathrm{nA}$.

4. The study of the phase composition of the main hydrosilicates of the hydrated cement matrix during its $\gamma$-irradiation and the effect of shot of titanium hydride on the change in the structure of the cement paste in the composite was carried out using X-ray phase analysis (XPA). $\mathrm{X}$-ray diffraction (XRD) was performed using $\mathrm{CuK} \alpha$ radiation with a Ni filter, on an ARL X1TRA X-ray diffractometer (Switzerland) using an ASTM file (USA). The spectra were recorded with an MSTR-4 ionization counter at angles from 14 to $56^{\circ}$. The diffraction patterns were measured with a RK-3A comparator. The XRD patterns of the sample being studied were processed separately for each shooting interval, using the PDWin program. Determination of the phase composition was carried out by analyzing the interplanar distance $d$ and the intensity of spectral reference lines.

5. X-ray fluorescence (XRF) analysis was performed on an ARL9900 Work Station XRF spectrometer (Switzerland) with a built-in diffraction system, a high-performance tube with an Rh anode, and a $50 \mu \mathrm{m}(75 \mu \mathrm{m})$ Be-window. The analysis software used was GuantAS, UniGuant, and OptiGuant. The XRF method is based on the excitation of the characteristic radiation of different elements in a sample using an external source (X-ray or isotope photon source), and registration of said characteristic radiation in the form of a line spectrum [40]. The position of the peaks in the $K, L$, and $M$-series of characteristic radiation on the energy scale is responsible for the identification of chemical elements in the sample, and the intensity of the peaks broadly represents the concentrations of elements.

\section{Results and Discussion}

External examination of the composite samples after irradiation showed that their integrity, color, and surface structure were all retained, in comparison with their initial state (Figure 5).

The results of studies of changes in the linear dimensions, strength, and density of composite specimens based on modified titanium hydride and Portland cement, after fast neutron irradiation at a fluence of $1.9 \times 10^{19}$ neutrons/ $\mathrm{cm}^{2}$, are presented in Table 2.

It follows from Table 2 that the geometry of the samples after irradiation did not change or changed only slightly. The maximum change in the height of the samples $(\Delta h)$ is $0.05 \%$ of the initial value. The maximum change in the average diameter $(d)$ is $0.09 \%$ of the initial value. All samples under investigation had reduced volume, associated with the removal of water bound in the hydrosilicate cement matrix. The average density of the samples prior to irradiation was $3.27 \mathrm{~g} / \mathrm{cm}^{3}$ and $3.28 \mathrm{~g} / \mathrm{cm}^{3}$ after irradiation. Changes in density (upward) of most of these samples are within the volume determination error. Thus, this work did not reveal obvious changes in the geometric and physicomechanical properties of composites based on modified titanium hydride and Portland cement after neutron irradiation. There does not appear to be a statistical significance.

According to SEM data (Figures 6-9), at an irradiation dose of more than $2 \mathrm{MGy}$, changes in the surface structure of the unmodified titanium hydride shot in the bulk of the cement composite and stratification (an increase in the interphase boundary) between the shot and the hydrated cement matrix occur due to the ongoing processes of dehydrogenation of the shot during radiogenic heating.

The released hydrogen creates channel microcracks and leads to the destruction of the composite structure. In this case, in a composite based on a modified shot of titanium hydride, no noticeable interphase disturbances occur up to an absorbed dose of $10 \mathrm{MGy}$. There is a visual anchoring of the filler surface with the cement matrix (Figures 6(b)-9(b)), which occurs due to significant adhesion of the cement matrix to the borosilicate modification shell of the titanium hydride shot.

Figure 10 shows data regarding changes in the strength properties of materials based on unmodified (UTHS) and modified (MTHS) shot of titanium hydride, under $\gamma$-irradiation with different dose loads.

The most significant decrease in strength occurs in a composite based on an unmodified fraction of titanium hydride at an absorbed dose of gamma irradiation of more than $2 \mathrm{MGy}$ (temperature $350^{\circ} \mathrm{C}$ ), which is associated with both thermal diffusion of hydrogen and dehydration of calcium hydrosilicates as a result of concomitant radiation heating.

Figures 11-14 show diffraction patterns of cement paste without a modified shot of titanium hydride and cement paste in a composite based on a modified shot of titanium hydride after $\gamma$-irradiation with a dose load from 1.0 to 10.0 MGy. 


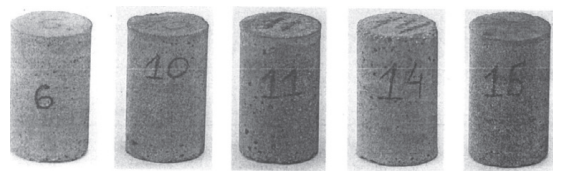

(a)

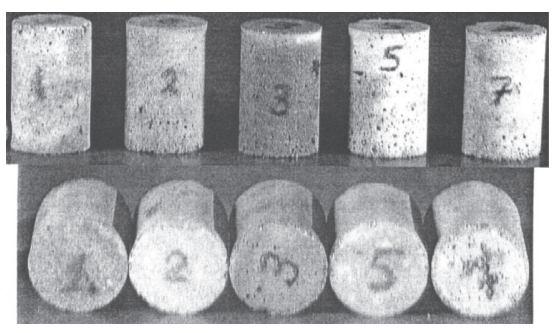

(b)

Figure 5: Appearance of composite material samples based on a modified shot of titanium hydride and Portland cement before (a) and after (b) irradiation with fast neutrons at a fluence of $1.9 \cdot 10^{19}$ neutrons $/ \mathrm{cm}^{2}$.

TABLE 2: Change in geometric and physicomechanical properties of irradiated composite samples.

\begin{tabular}{lccccc}
\hline Composite sample & Compressive strength $\mathrm{R}_{\text {com }}[\mathrm{MPa}]$ & Density $\left[\mathrm{g} / \mathrm{cm}^{3}\right]$ & Height $(h)(\mathrm{mm})$ & Diameter $(\mathrm{d})(\mathrm{mm})$ & $\left.\mathrm{Volume}(\mathrm{V})(\mathrm{mm})^{3}\right)$ \\
\hline Before irradiation & $35.5 \pm 1.8$ & $3.27 \pm 0.03$ & $44.47 \pm 0.04$ & $22.16 \pm 0.07$ & $17220 \pm 85$ \\
After irradiation & $33.5 \pm 1.8$ & $3.28 \pm 0.03$ & $44.46 \pm 0.04$ & $22.14 \pm 0.05$ & $17139 \pm 56$ \\
\hline
\end{tabular}

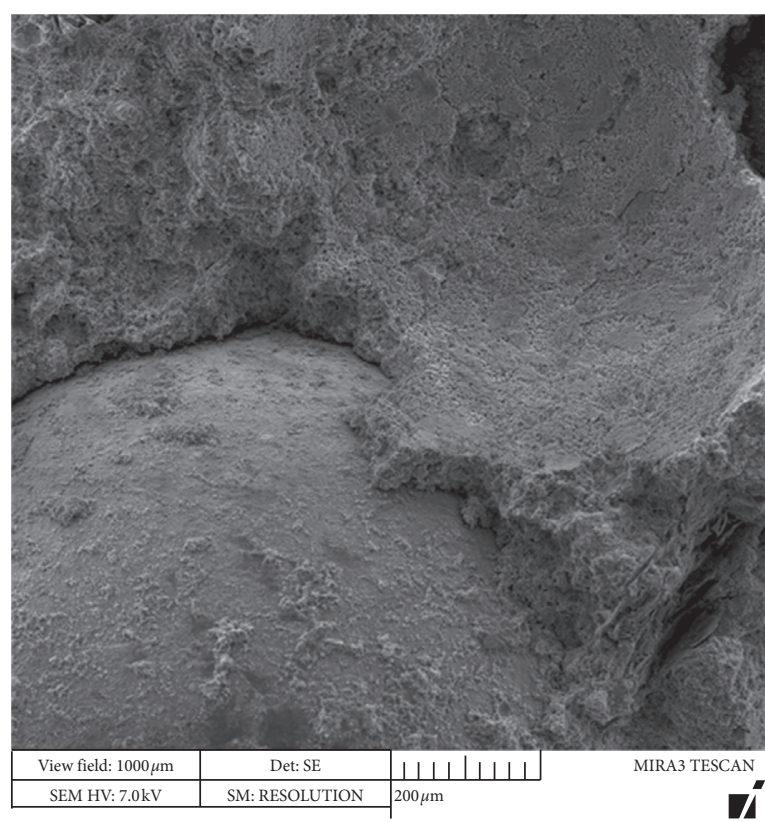

(a)

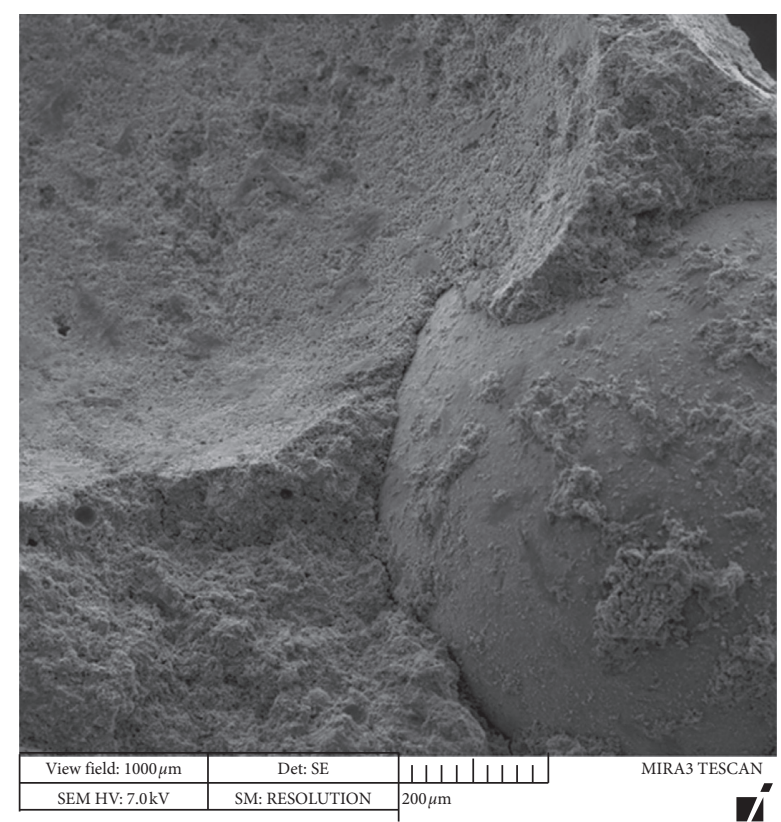

(b)

FiguRE 6: Surface microstructure (SEM) of a fracture of a cement composite based on unmodified (a) and modified (b) shot of titanium hydride subjected to $\gamma$-irradiation, at a dose $D=1 \mathrm{MGy}$.

Analysis of the data showed that modified titanium hydride introduces some changes in the structure of the hydrosilicate phases of the cement paste, at absorbed $\gamma$-irradiation doses of 1.0-2.0 MGy.

At a dose of $2 \mathrm{MGy}$, the presence of a modified shot of titanium hydride contributes to the formation of low-basicity calcium hydrosilicates in the system, in the form of bar-like crystalline rods $\mathrm{Ca}_{2} \mathrm{Si}_{2} \mathrm{O}_{5}(\mathrm{OH})_{2} \cdot \mathrm{H}_{2} \mathrm{O}$ (Figure 15). According to known data [41], this can lead to compaction of cement paste and a decrease in its water and gas permeability.

Analysis of diffraction patterns of irradiated composites at a dose of 5-10 MGy showed the formation of silicate phases of the same chemical composition and crystallographic parameters in the cement paste and cement paste in the composition of the composite based on the modified shot of titanium hydride.

The electronic structure of titanium atoms in the composition of the composite was estimated using XRF, for various dose loads of $\gamma$ radiation. Titanium is characterized by electronic transitions of the $M, \mathrm{~L} \longrightarrow \mathrm{K}$ type, and by the appearance of $K_{\alpha}$ and $K_{\beta}$ lines in the XRF spectrum (Figure 16). The parameters of XRF spectra of titanium atoms in a composite subjected to $\gamma$-irradiation, with an absorbed dose of $0.5-10.0 \mathrm{MGy}$, are presented in Table 3. 


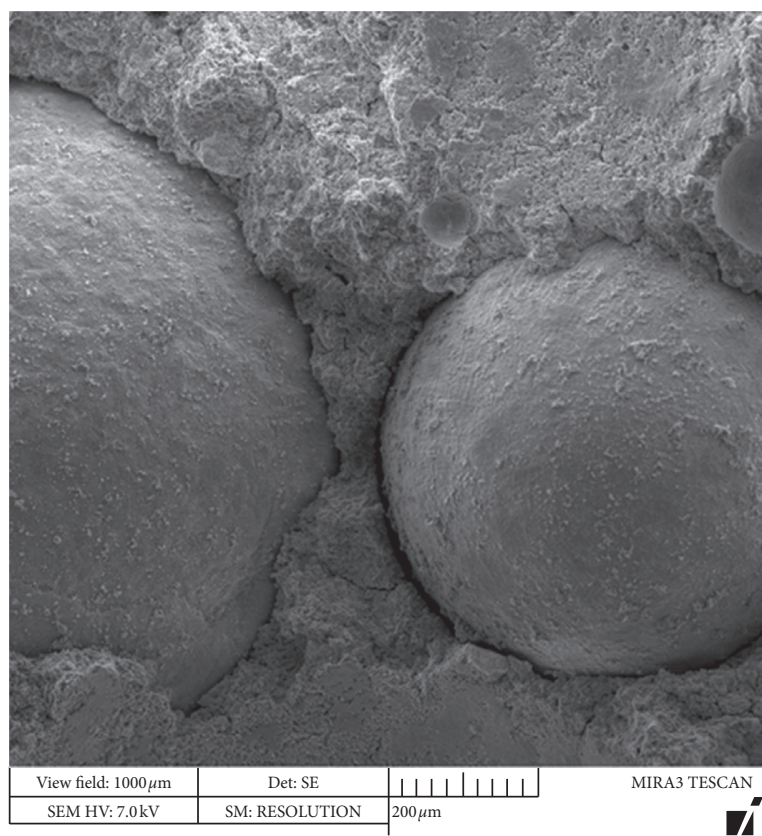

(a)

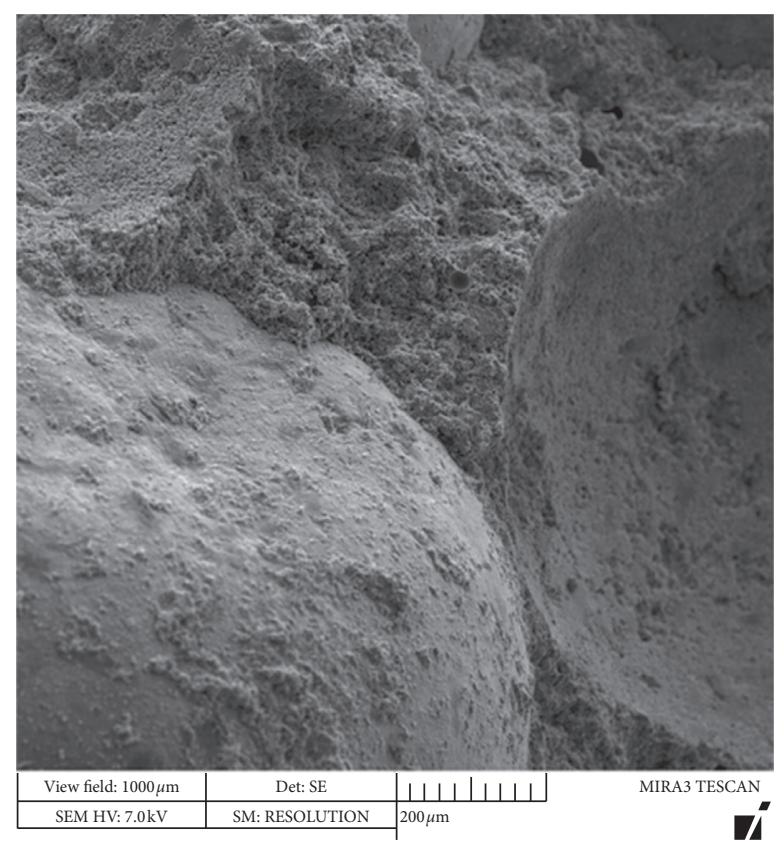

(b)

FIGURE 7: Surface microstructure (SEM) of a fracture of a cement composite chip based on unmodified (a) and modified (b) shot of titanium hydride subjected to $\gamma$-irradiation, at a dose $D=2 \mathrm{MGy}$.

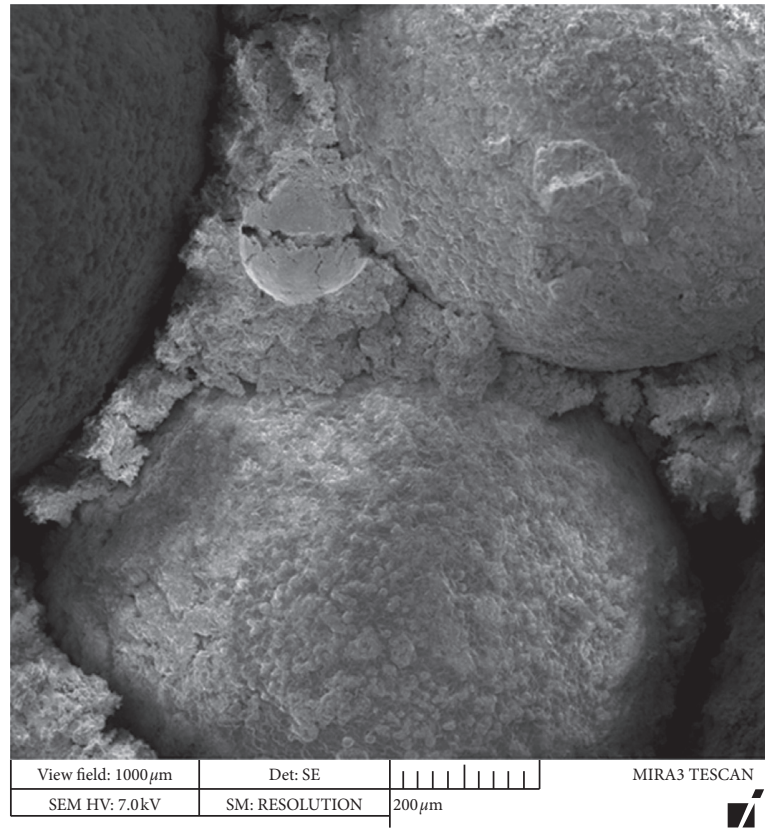

(a)

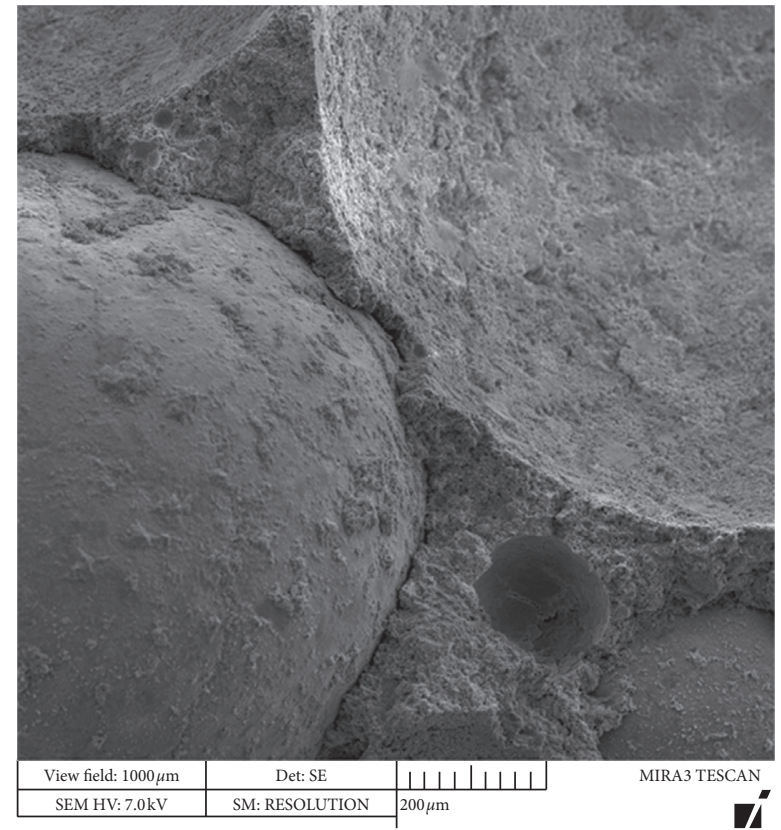

(b)

FIGURE 8: Surface microstructure (SEM) of a fracture of a cement composite chip based on unmodified (a) and modified (b) shot of titanium hydride subjected to $\gamma$-irradiation, at a dose $D=5 \mathrm{MGy}$.

With an absorbed dose of $\gamma$ radiation from 0.5 to 2.0 MGy, the intensity of the $K_{\alpha}$ and $K_{\beta}$ lines of the XRF spectrum decreases by an average of $5.2 \%$ (Figure 17).

A significant increase in fluorescence in the titanium atom at $5.0 \mathrm{MGy}$ (by $31 \%$ for $K_{\alpha}$ lines and $51 \%$ for $K_{\beta}$ lines) indicates the intensity of the electron-photon interaction. The change in fluorescence intensity is also associated with the selective excitation of titanium atoms under $\gamma$ and X-ray-irradiation, which, in turn, may be due to structural and phase changes in titanium hydride, due to 


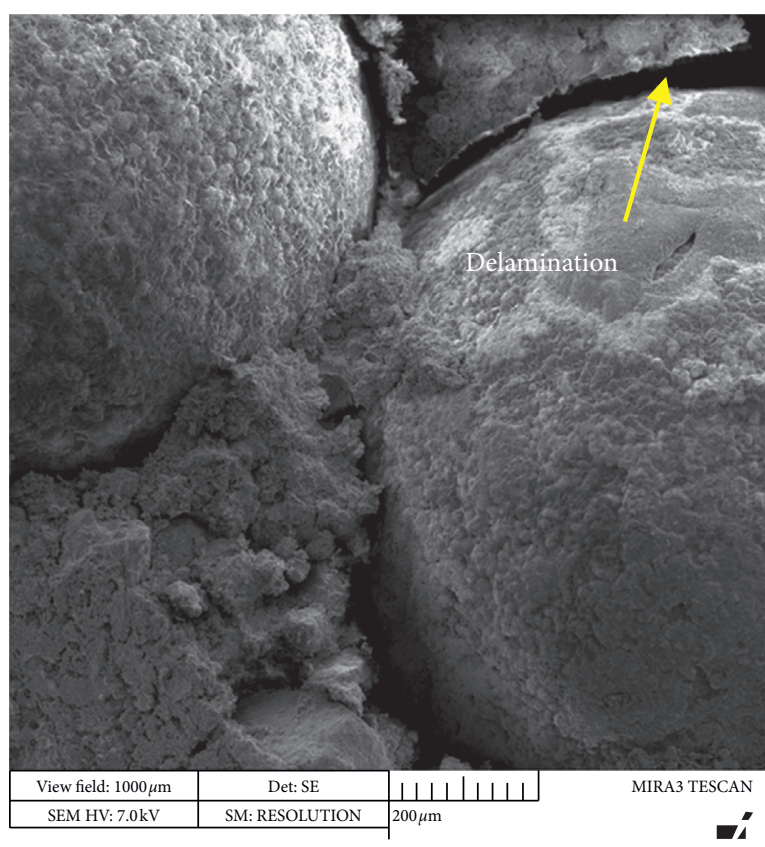

(a)

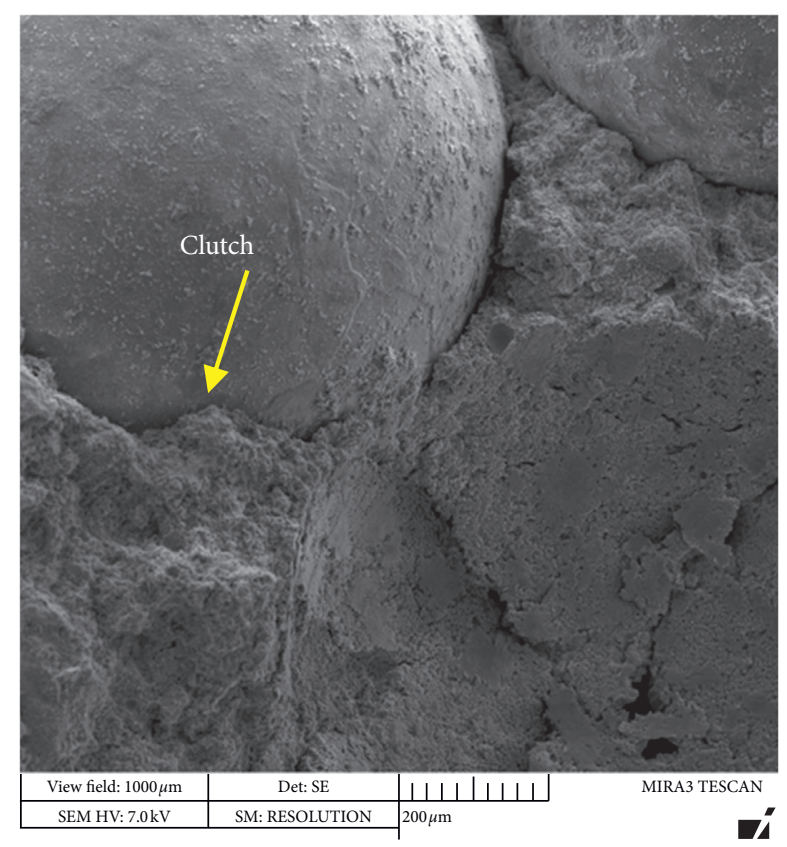

(b)

FIGURE 9: Surface microstructure (SEM) of a fracture of a cement composite chip based on unmodified (a) and modified (b) shot of titanium hydride subjected to $\gamma$-irradiation, at a dose $D=10 \mathrm{MGy}$.

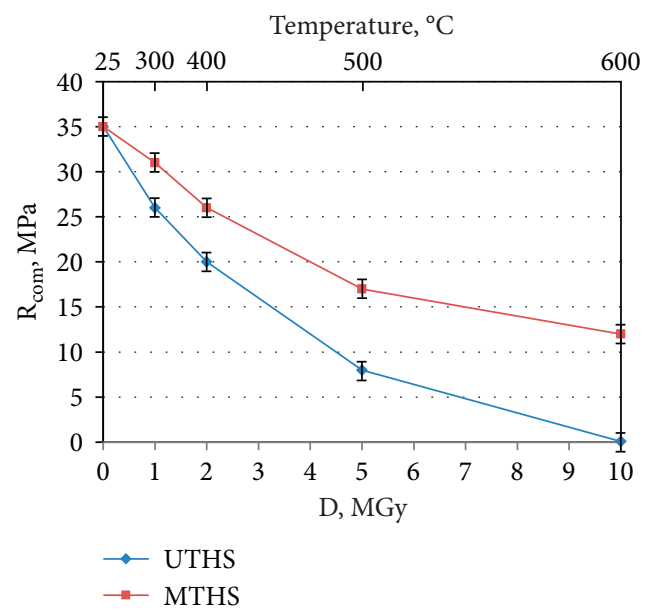

FIGURE 10: Strength of titanium hydride composites subjected to $\gamma$-irradiation.

the diffusion of hydrogen from the bulk of the shot into the surface layers. In this case, a shift of the $K_{\alpha}$ and $K_{\beta}$ lines to the high-energy region of the spectrum $(E=4.49 \mathrm{eV})$ is observed.
A continuous change in the intensity ratio of the $K_{\alpha} / K_{\beta}$ excitation lines over the entire range of dose loads indicates a redistribution of the electron density in titanium hydride, under the action of $\gamma$ learning. 


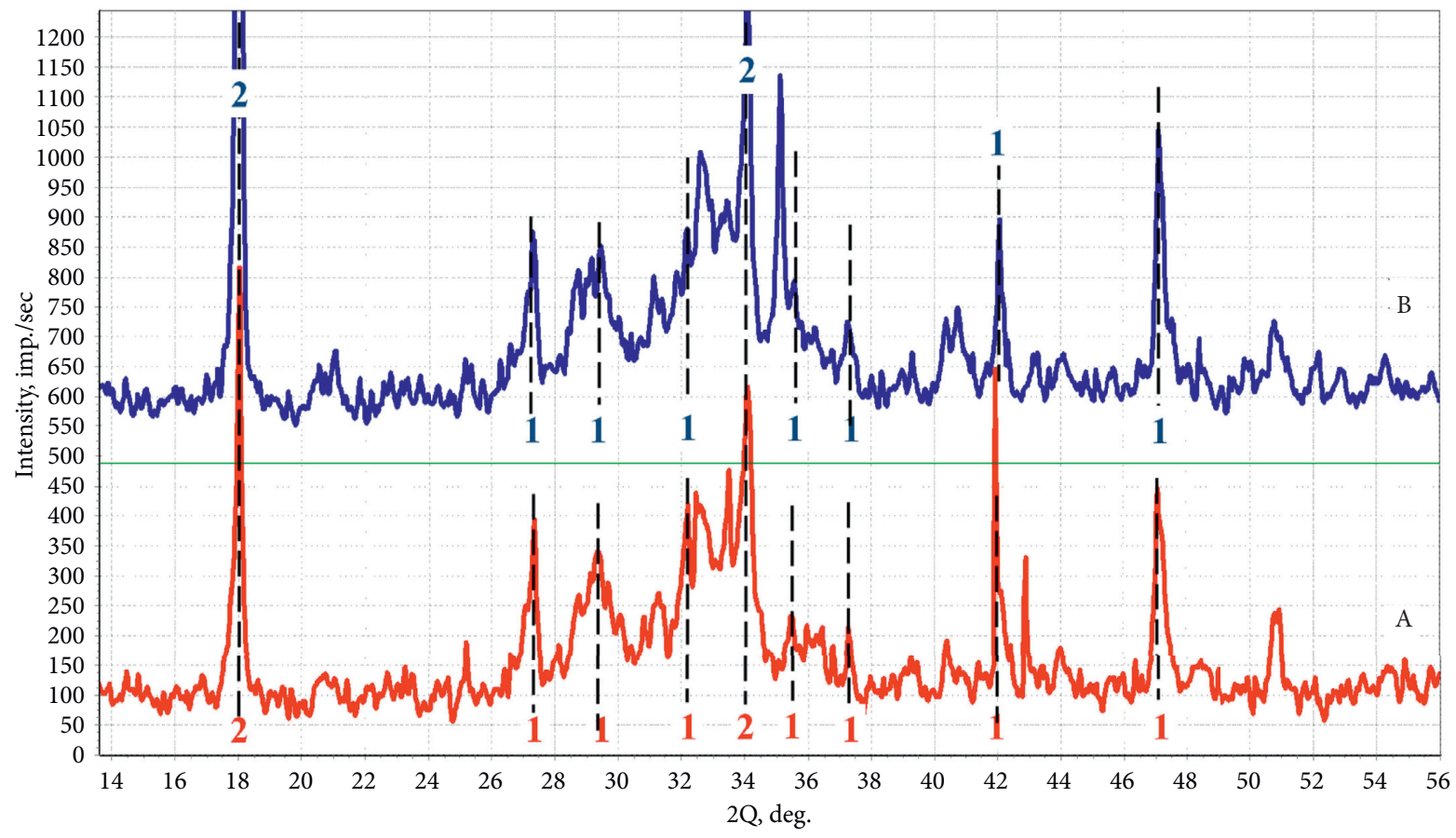

Figure 11: Diffraction patterns of cement paste (A) and cement paste in a composite based on a modified shot of titanium hydride (B), subjected to $\gamma$-irradiation dose $D=1 \mathrm{MGy}: 1-2 \mathrm{CaO} \cdot \mathrm{SiO}_{2} \cdot \mathrm{H}_{2} \mathrm{O} ; 2-\mathrm{Ca}(\mathrm{OH})_{2}$.

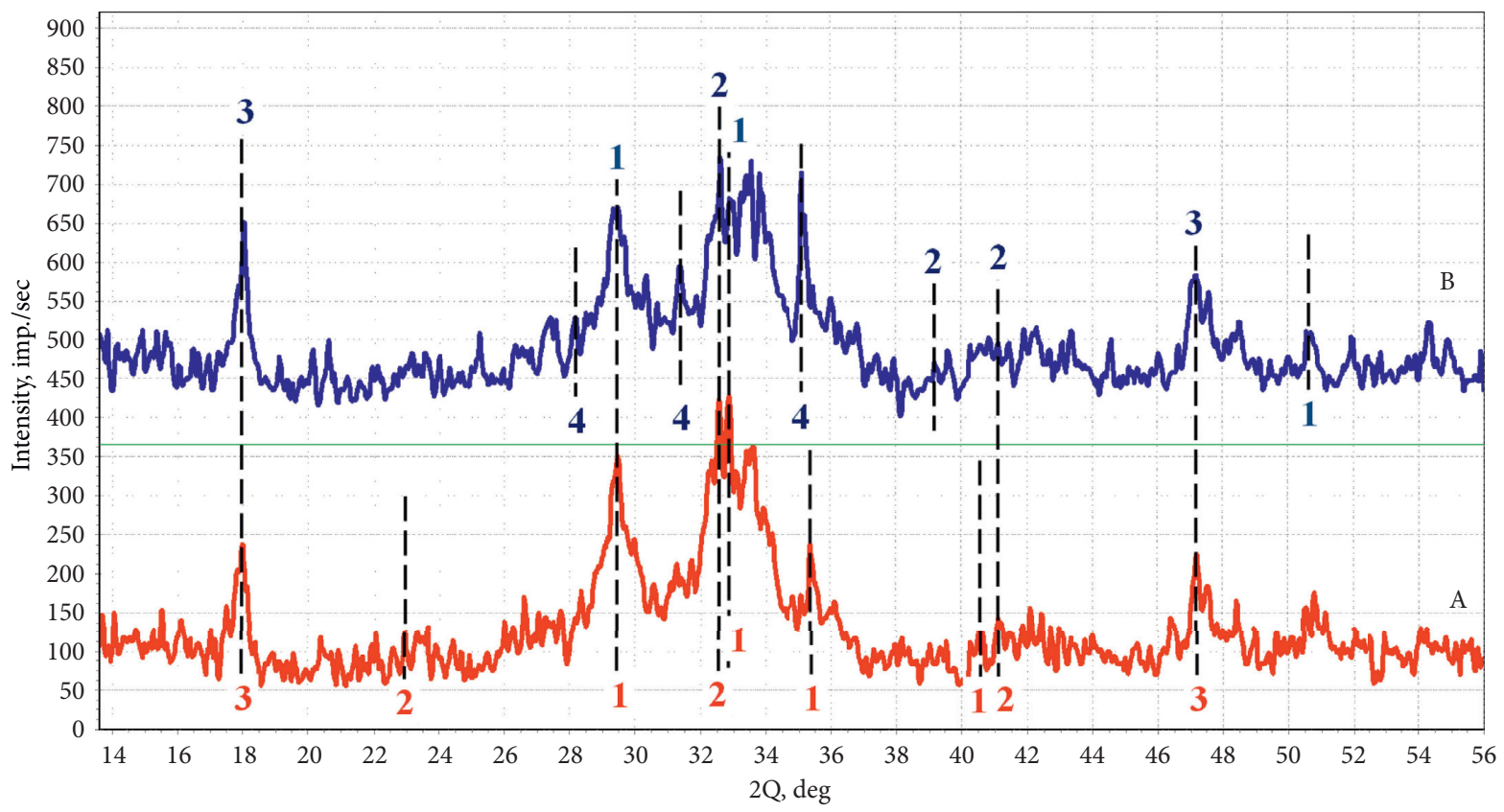

Figure 12: Diffraction patterns of hardened Portland cement paste (A) and cement paste in a composite based on a modified shot of titanium hydride (B), subjected to $\gamma$-irradiation dose $\mathrm{D}=2 \mathrm{MGy}$ : $1-2 \mathrm{Ca}_{3} \mathrm{Si}_{2} \mathrm{O}_{7} \cdot \mathrm{H}_{2} \mathrm{O} ; 2-\mathrm{Ca}_{2} \mathrm{SiO}_{4} ; 3-\mathrm{Ca}(\mathrm{OH})_{2} ; 4-\mathrm{Ca}_{2} \mathrm{Si}_{2} \mathrm{O}_{5}(\mathrm{OH})_{2} \cdot \mathrm{H}_{2} \mathrm{O}$. 


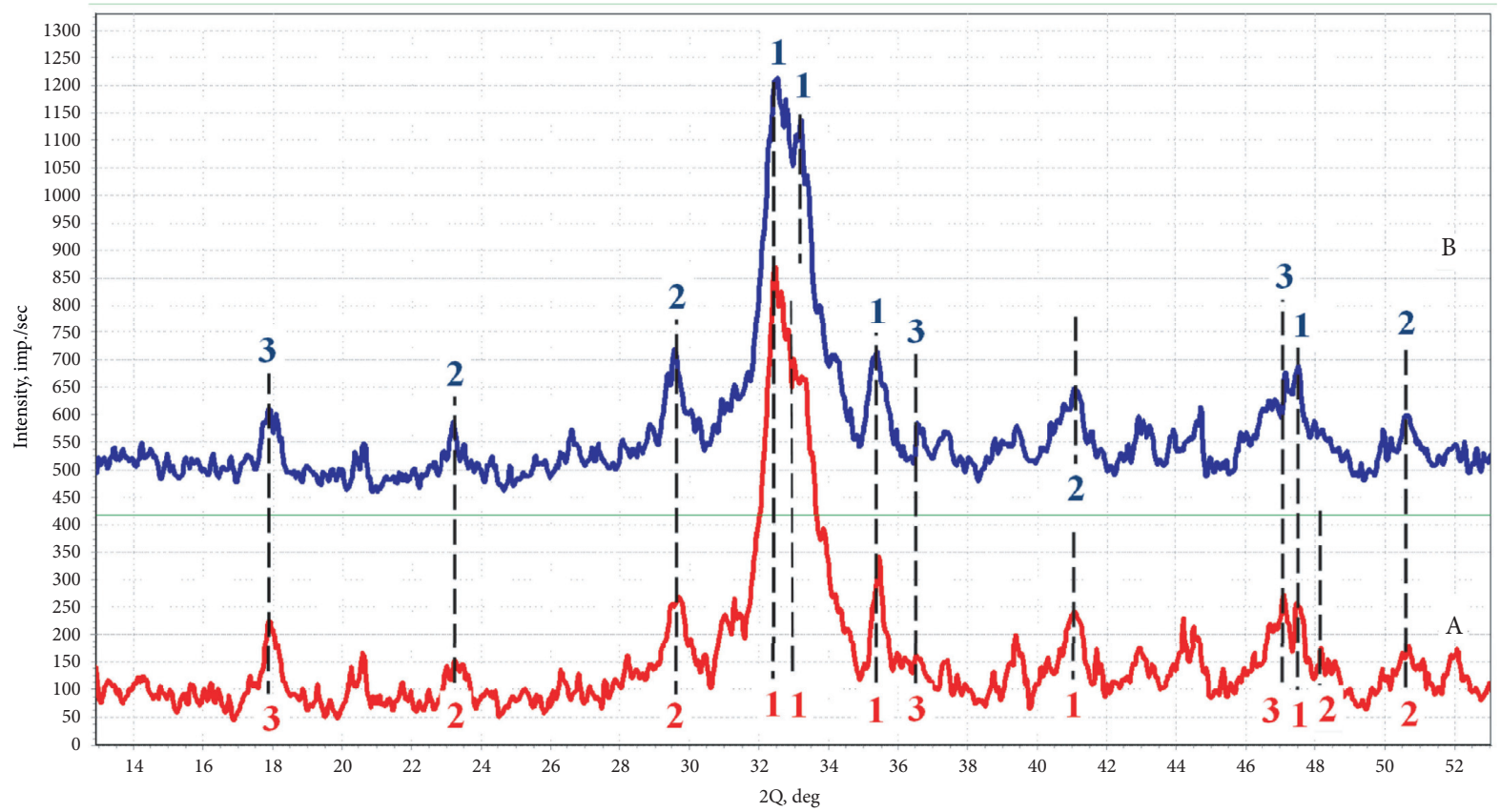

Figure 13: Diffraction patterns of cement paste (A) and cement paste in a composite based on a modified shot of titanium hydride (B), subjected to $\gamma$-irradiation dose $D=5 \mathrm{MGy}$ : $1-\mathrm{Ca}_{2} \mathrm{SiO}_{4} \cdot 0,3 \mathrm{H}_{2} \mathrm{O} ; 2-\mathrm{Ca}_{2} \mathrm{SiO}_{4} ; 3-\mathrm{Ca}(\mathrm{OH})_{2}$.

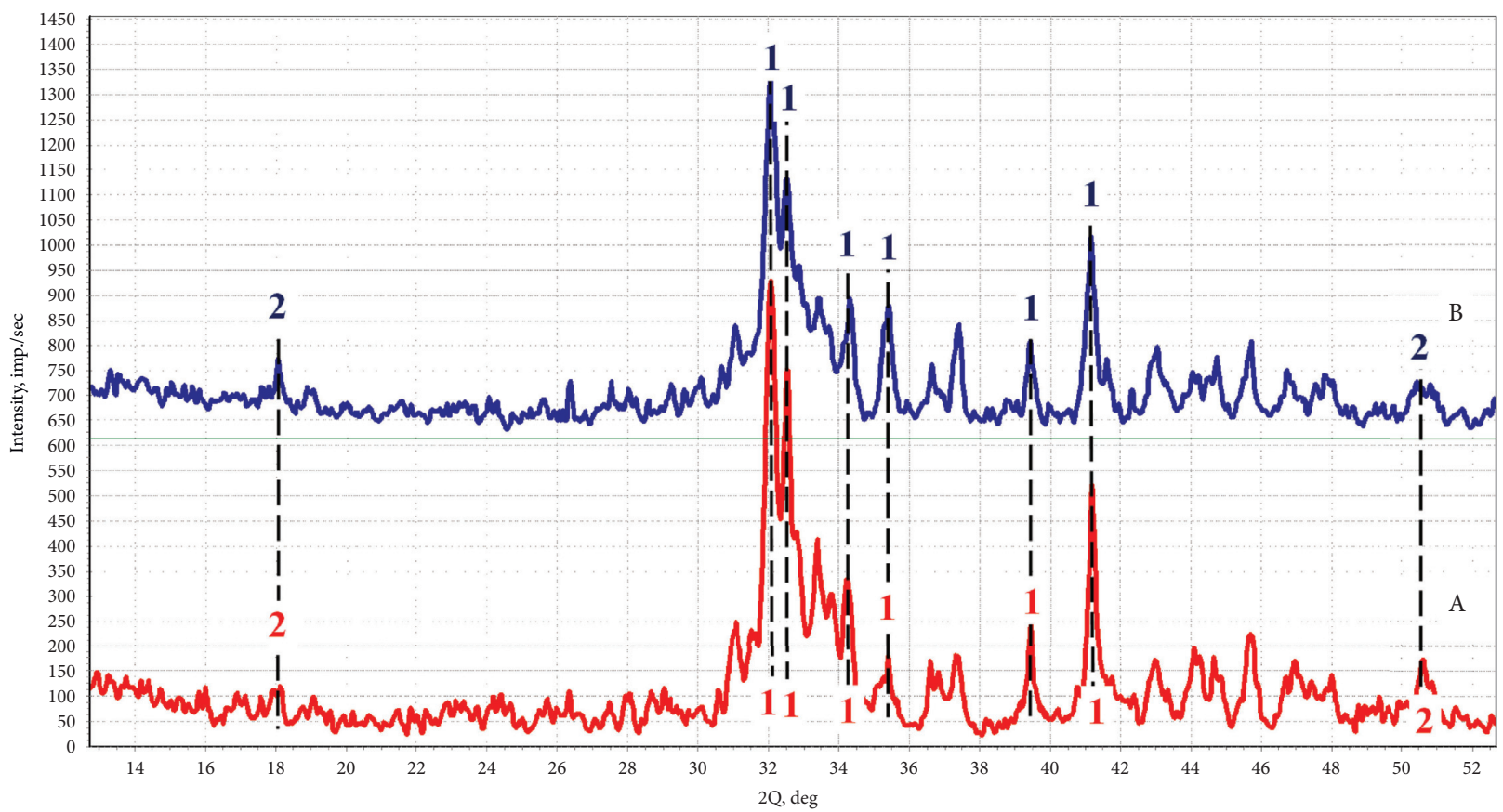

Figure 14: Diffraction patterns of cement paste (A) and cement paste in a composite based on a modified shot of titanium hydride (B), subjected to $\gamma$-irradiation dose $D=10 \mathrm{MGy}: 1-\mathrm{Ca}_{2} \mathrm{SiO}_{4} ; 2-\mathrm{Ca}(\mathrm{OH})_{2}$. 


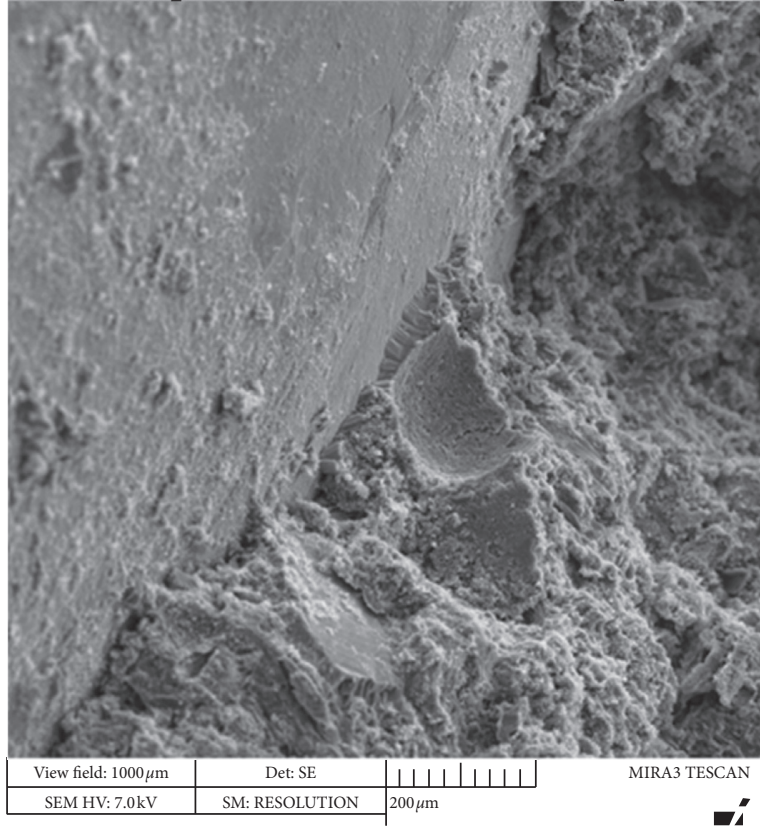

(a)

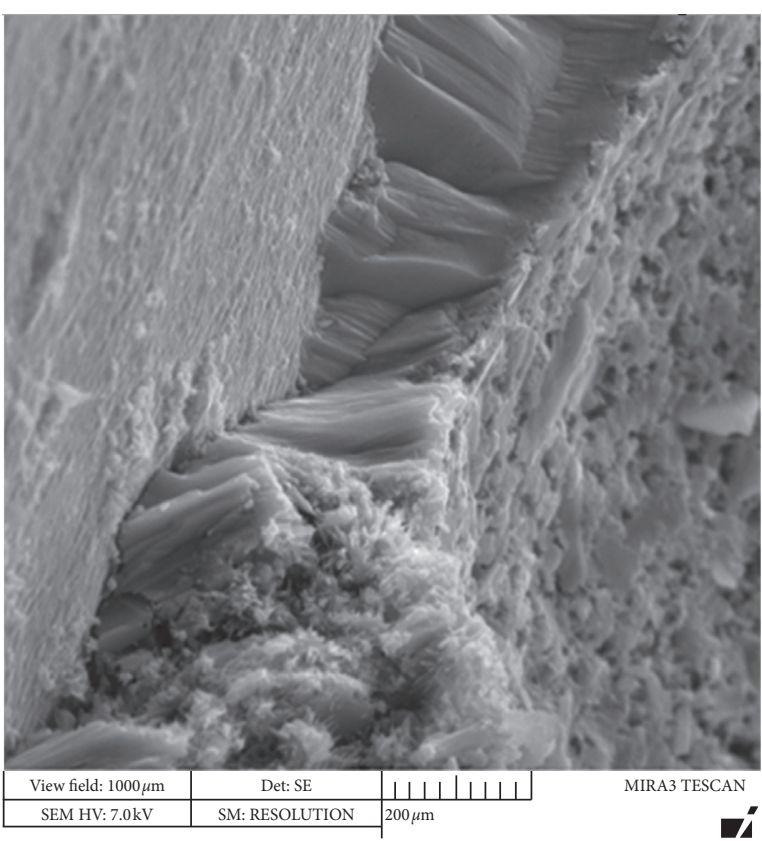

(b)

FIGURE 15: Microstructure of the cleavage surface of a composite based on a modified shot of titanium hydride, subjected to $\gamma$-irradiation at a dose of $D=2$ MGy (SEM): (a) 2500x magnification; (b) 25000x magnification.

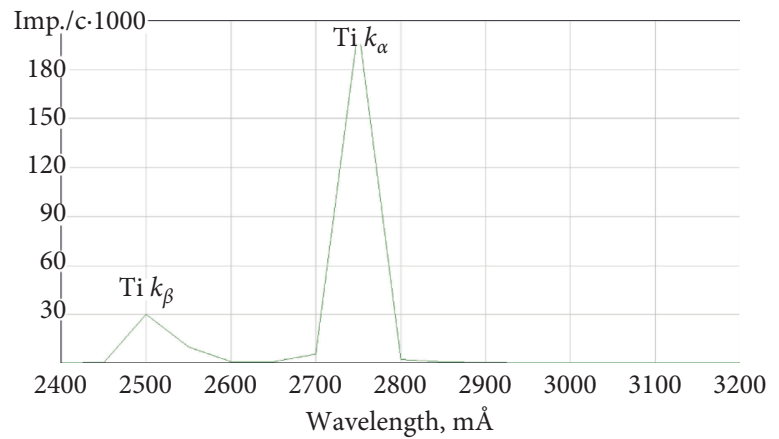

FIGURE 16: XRF spectrum of titanium atoms, in a composite heat-treated at $300^{\circ} \mathrm{C}$.

TABLE 3: Parameters of XRF spectra of titanium atoms, in a composite subjected to $\gamma$-irradiation.

\begin{tabular}{|c|c|c|c|c|}
\hline Dose $D[\mathrm{MGy}]$ & $\lambda(\mathrm{m} \AA)$ & $I$ (imp./c) & $\Delta_{1 / 2}(\mathrm{~m} \AA)$ & $I_{\alpha} / I_{\beta}$ \\
\hline \multirow[b]{2}{*}{0} & $K_{\alpha}, 2749.1$ & 189233.5 & 48.6 & \multirow{2}{*}{5.32} \\
\hline & $K_{\beta}, 2515.1$ & 35538.4 & 58.6 & \\
\hline \multirow{2}{*}{0.5} & $K_{\alpha}, 2749.2$ & 211035.6 & 49.4 & \multirow{2}{*}{5.20} \\
\hline & $K_{\beta}, 2515.4$ & 40585.5 & 59.8 & \\
\hline \multirow{2}{*}{1.0} & $K_{\alpha}, 2749.2$ & 202131.8 & 49.1 & \multirow{2}{*}{5.17} \\
\hline & $K_{\beta}, 2515.2$ & 39088.7 & 58.9 & \\
\hline \multirow{2}{*}{2.0} & $K_{\alpha}, 2749.0$ & 200174.9 & 48.9 & \multirow{2}{*}{5.26} \\
\hline & $K_{\beta}, 2515.3$ & 38053.3 & 58.1 & \\
\hline \multirow{2}{*}{5.0} & $K_{\alpha}, 2749.0$ & 263176.9 & 52.4 & \multirow{2}{*}{4.57} \\
\hline & $K_{\beta}, 2515.3$ & 57547.1 & 63.6 & \\
\hline \multirow{2}{*}{10.0} & $K_{\alpha}, 2749.4$ & 208521.0 & 49.2 & \multirow{2}{*}{5.33} \\
\hline & $K_{\beta}, 25151.8$ & 39116.2 & 59.6 & \\
\hline
\end{tabular}



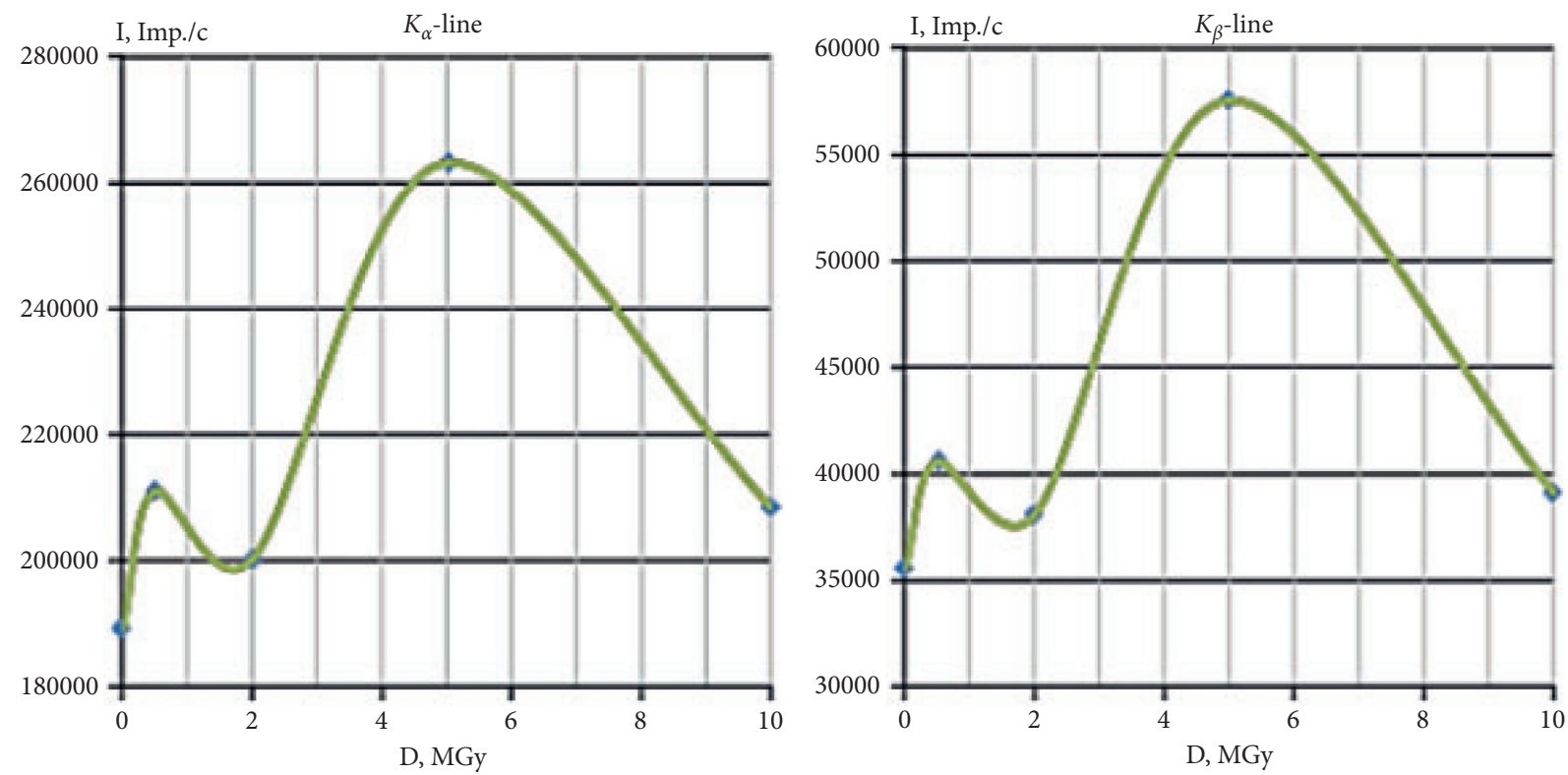

FIGURE 17: Changes in the fluorescence intensity of the $K_{\alpha}$ and $K_{\beta}$ lines of the titanium atom, in a composite based on modified titanium hydride under the action of $\gamma$ irradiation.

\section{Conclusions}

A composite material based on a modified shot of titanium hydride and Portland cement, hydrated under hydrothermal conditions, has a high radiation resistance when irradiated with fast neutrons. In a flow of fast neutrons with energy $>0.5 \mathrm{MeV}$, at a fluence of $1.9 \times 10^{19}$ neutrons $/ \mathrm{cm}^{2}$, the material retains its integrity, color, and surface structure in comparison with the initial state. Evaluation of the geometric and physicomechanical properties of the irradiated composite samples did not reveal any obvious changes after irradiation with fast neutrons.

The use of a modified shot of titanium hydride increases the radiation resistance of the cement composite in a high-energy $\gamma$-ray stream, compared to an unmodified shot. The homogeneity of the composite structure is maintained, up to an absorbed dose of $\gamma$ radiation of 10 MGy. The presence of a modified shot of titanium hydride in the cement composite under $\gamma$-irradiation dose loads of 1-2 MGy leads to the formation of lowbasicity hydrosilicates, which does not significantly affect the geometric nor strength properties of the cement paste.

Evaluation of the electronic structure of titanium atoms in the cement composite by the XRF method showed that, under the action of $\gamma$-irradiation, a redistribution of electron density occurs in the hydride phase of the titanium hydride. This is caused by structural and phase changes in the modified titanium hydride, due to the ongoing dehydrogenation processes at increased radiation loads.

\section{Data Availability}

The data are available on request to R. N. Yastrebinsky (astrebinskiy.rn@bstu.ru).

\section{Conflicts of Interest}

The authors declare that there are no conflicts of interest regarding the publication of this paper.

\section{Acknowledgments}

The work was carried out within the framework of the State Assignment of the Ministry of Education and Science of the Russian Federation, Project no. 0625-2020-0011.

\section{References}

[1] A. B. Tsepelev, A. S. Ilyushin, T. Y. Kiseleva, E. A. Brovkina, and V. N. Melnikov, "Radiation-induced changes in the structure and mechanical properties of Fe-Mo alloy under electron irradiation," Inorganic Materials: Applied Research, vol. 8, no. 3, pp. 378-381, 2017.

[2] Y. Khmurovska and P. Štemberk, "Mechanisms behind radiation-induced deterioration of concrete," IOP Conference Series: Materials Science and Engineering, vol. 596, p. 012035, 2019.

[3] D. Toyen, E. Wimolmala, N. Sombatsompop, T. Markpin, and K. Saenboonruang, "Sm2O3/UHMWPE composites for radiation shielding applications: mechanical and dielectric properties under gamma irradiation and thermal neutron shielding," Radiation Physics and Chemistry, vol. 164, p. 108366, 2019.

[4] Q. An, A. Elshafiey, L. Huang, D. A. Hammer, and M. Hassani, "Plasma and X-ray radiation-induced damage mechanisms in a tungsten heavy alloy," Journal of Nuclear Materials, vol. 539, p. 152325, 2020.

[5] W. Hoffelner, "Irradiation damage in nuclear power plants," in Handbook of Damage Mechanics, G. Voyiadjis, Ed., Springer, New York, NY, USA, 2015.

[6] G. Vértesy, A. Gasparics, I. Uytdenhouwen, I. Szenthe, F. Gillemot, and R. Chaouadi, "Nondestructive investigation 
of neutron irradiation generated structural changes of reactor steel material by magnetic hysteresis method," Metals, vol. 10, p. 642, 2020.

[7] S. E. Arbuzov, V. L. Danilov, B. N. Goshchitskii, A. E. Kar'kin, and V. D. Parkhomenko, "Separation of radiation defects in $\mathrm{Ni}$ and Ni-C alloys under electron and neutron irradiation," IOP Conference Series: Materials Science and Engineering, vol. 110, p. 012034, 2016.

[8] J. Kwon, H.-H. Jin, G.-G. Lee, and D.-H. Park, "Radiation damage to Ni-based alloys in Wolsong CANDU reactor environments," Nuclear Engineering and Technology, vol. 51, no. 3, pp. 915-921, 2019.

[9] I. M. Neklyudov, O. V. Borodin, V. V. Bryk, and V. N. Voyevodin, "Problem of radiation resistance of structural materials of nuclear power," in Progress in High Energy Physics and Nuclear Safety. NATO Science for Peace and Security Series B: Physics and Biophysics, V. Begun, L. L. Jenkovszky, and A. Polański, Eds., Springer, Dordrecht, Netherlands, 2009.

[10] O. El-Atwani, N. Li, M. Li et al., "Outstanding radiation resistance of tungsten-based high-entropy alloys," Science Advances, vol. 5, 2019.

[11] L. Wei, Y. Li, G. Zhao, Q. Zheng, J. Li, and Z. Zeng, "Key factors in radiation tolerance of BCC metals under steady state," Nuclear Instruments and Methods in Physics Research Section B: Beam Interactions with Materials and Atoms, vol. 455, pp. 134-139, 2019.

[12] A. Tolstoy, "Fine-grained high-strength concrete," Construction Materials and Products, vol. 3, no. 1, pp. 39-43, 2020, in Russian.

[13] S. A. Abo-El-Enein, F. I. El-Hosiny, S. M. A. El-Gamal, M. S. Amin, and M. Ramadan, "Gamma radiation shielding, fire resistance and physicochemical characteristics of Portland cement pastes modified with synthesized Fe2O3 and $\mathrm{ZnO}$ nanoparticles," Construction and Building Materials, vol. 173, pp. 687-706, 2018.

[14] T. A. Almeida Junior, M. S. Nogueira, V. Vivolo, M. P. A. Potiens, and L. L. Campos, "Mass attenuation coefficients of X-rays in different barite concrete used in radiation protection as shielding against ionizing radiation," Radiation Physics and Chemistry, vol. 140, pp. 349-354, 2017.

[15] D. V. Anopko, O. A. Honchar, M. O. Kochevykh, and L. O. Kushnierova, "Radiation protective properties of finegrained concretes and their radiation resistance," IOP Conference Series: Materials Science and Engineering, vol. 907, p. 012031, 2020.

[16] H. Hilsdorf, J. Kropp, and H. Koch, "The effects of nuclear radiation on the mechanical properties of concrete," American Concrete Institute, ACI Special Publication, vol. 55, 1978.

[17] B. Gray, "Effects of reactor radiation on cements and concrete," in Results of Concrete Irradiation Programmes, pp. 17-40, Commission of the European Communities, Brussels, Belgium, 1972.

[18] F. Vodak, V. Vydra, K. Trtík, and O. Kapickova, "Effect of gamma irradiation on hardened cement paste," in Proceedings of the Second International Conference on Sustainable Construction Materials and Technologies, Universita Politecnica delle Marche, Ancona, Italy, June 2010.

[19] F. Vodák, K. Trtík, V. Sopko, O. Kapičková, and P. Demo, "Effect of $\gamma$-irradiation on strength of concrete for nuclearsafety structures," Cement and Concrete Research, vol. 35, no. 7, pp. 1447-1451, 2005.

[20] P. Bouniol and A. Aspart, "Disappearance of oxygen in concrete under irradiation: the role of peroxides in radiolysis,"
Cement and Concrete Research, vol. 28, no. 11, pp. 1669-1681, 1998.

[21] B. Kelly, J. Brocklehurst, D. Mottershead, S. McNearney, and I. Davidson, "The effects of reactor radiation on concrete," in Proceedings of the 2nd Conference on Prestressed Concrete Pressure Vessels and Their Insulation, London, UK, March 1969.

[22] J. K. Thomas, "Physical aspects of photochemistry and radiation chemistry of molecules adsorbed on silica, gammaalumina, zeolites, and clays," Chemical Reviews, vol. 93, no. 1, pp. 301-320, 1993.

[23] N. A. Eissa, M. S. I. Kany, A. S. Mohamed, A. A. Sallam, and M. H. El Fouly, "Mossbauer spectroscopic study of gamma irradiation on the structural properties of Hematite, Magnetite and Limonite concrete for nuclear reactor shielding," Hyperfine Interactions, vol. 112, no. 1/4, pp. 205-212, 1998.

[24] T. Ichikawa and H. Koizumi, "Possibility of radiation-induced degradation of concrete by alkali-silica reaction of aggregates," Journal of Nuclear Science and Technology, vol. 39, no. 8, pp. 880-884, 2002.

[25] S. Le Caër, "Water radiolysis: influence of oxide surfaces on $\mathrm{H}_{2}$ production under ionizing radiation," Water, vol. 3, pp. 235-253, 2011.

[26] Y. Reches, "A multi-scale review of the effects of gamma radiation on concrete," Results in Materials, vol. 2, p. 100039 , 2019.

[27] D. Jóźwiak-Niedźwiedzka and P. A. Lessing, S. Mindess, "9high-density and radiation shielding concrete," in Woodhead Publishing Series in Civil and Structural Engineering, Developments in the Formulation and Reinforcement of Concrete, pp. 193-228, Woodhead Publishing, Cambridge, UK, Second edition, 2019.

[28] J. M. Leys, A. Zarins, J. Cipa, L. Baumane, G. Kizane, and R. Knitter, "Radiation-induced effects in neutron- and electron-irradiated lithium silicate ceramic breeder pebbles," Journal of Nuclear Materials, vol. 540, p. 152347, 2020.

[29] G. Bonny, M. J. Konstantinovic, A. Bakaeva et al., "Trends in vacancy distribution and hardness of high temperature neutron irradiated single crystal tungsten," Acta Materialia, vol. 198, pp. 1-9, 2020.

[30] A. Holmes-Siedle and V. A. J. van Lint, R. A. Meyers, "Radiation effects in electronic materials and devices," Encyclopedia of Physical Science and Technology, pp. 523-559, Academic Press, Cambridge, MA, USA, Third edition, 2003.

[31] A. M. Shulpekov, O. K. Lepakova, and N. I. Radishevskaya, "Phase-and structural formation in the $\mathrm{TiO}_{2}-\mathrm{Al}-\mathrm{C}$ system in the SHS process," Chemical Bulletin, vol. 1, pp. 4-11, 2018, in Russian.

[32] V. V. Larionov, V. A. Varlachev, and X. Shupeng, "Accumulation of hydrogen in titanium exposed to neutron irradiation," International Journal of Hydrogen Energy, vol. 45, no. 30, pp. 15294-15301, 2020.

[33] R. N. Yastrebinsky, V. I. Pavlenko, A. A. Karnauhov, N. I. Cherkashina, and A. V. Yastrebinskaya, "Thermal stability of titanium hydride modified by the electrochemical deposition of titanium metal," Materials Research Express, vol. 7, Article ID 106519, 2020.

[34] R. N. Yastrebinsky, "Decrease gripping gamma-radiation scale composite neutron and protective material on the basis of the modified hydride of the titan with various content of atoms of bor," Problems of Atomic Science and Technology, vol. 4, no. 110, pp. 103-106, 2017.

[35] V. I. Pavlenko, G. G. Bondarenko, O. V. Kuprieva, R. N. Yastrebinskii, and N. I. Cherkashina, "Modification of 
titanium hydride surface with sodium borosilicate," Inorganic Materials: Applied Research, vol. 5, no. 5, pp. 494-497, 2014.

[36] R. N. Yastrebinsky, V. I. Pavlenko, A. V. Yastrebinskaya, and N. A. Denisova, "Structural-phase transformations in heattreated thin film borosiloxanes," Bulletin of BSTU Named After V.G. Shukhov, vol. 11, pp. 117-122, 2017, in Russian.

[37] V. I. Pavlenko, N. I. Cherkashina, R. N. Yastrebinsky, and O. V. Demchenko, "On enhancing the thermal stability of metal hydrides by ion-plasma vacuum magnetron sputtering," Journal of Surface Investigation: X-Ray, Synchrotron and Neutron Techniques, vol. 11, no. 1, pp. 254-258, 2017.

[38] V. I. Pavlenko, O. V. Kuprieva, N. I. Cherkashina, and R. N. Yastrebinskii, "Defects in modified titanium hydride crystals subjected to heat treatment," Russian Physics Journal, vol. 58, no. 5, pp. 724-729, 2015.

[39] T. Westermann, "ANSYS-Simulationen-Projektarbeiten," in Modellbildung und Simulation, Springer, Berlin, Heidelberg, 2010.

[40] M. Yao, D. Wang, and M. Zhao, "Element analysis based on energy-dispersive X-ray fluorescence," Advances in Materials Science and Engineering, vol. 2015, Article ID 290593, 7 pages, 2015.

[41] E. Tajuelo Rodriguez, W. A. Hunnicutt, P. Mondal, and Y. Le Pape, "Examination of gamma-irradiated calcium silicate hydrates. part I: chemical-structural properties," Journal of the American Ceramic Society, vol. 103, pp. 1-11, 2019. 